\title{
A Compact Balanced Antipodal Bow-Tie Antenna Having Double Notch-Bands
}

\author{
AbdolmehdiDadgarpour ${ }^{1}$, Farid Jolani ${ }^{2}$, Yiqiang $\mathrm{Yu}^{2,3}$, Zhizhang Chen ${ }^{2}$, \\ Tayeb A. Denidni ${ }^{1}$, Bal S. Virdee ${ }^{4}$
}

\begin{abstract}
${ }^{1}$ Université du Québec, INRS-EMT, Montréal, QC, Canada (email: abdolmehdi.dadgarpour@emt.inrs.ca, denidni@emt.inrs.ca) ${ }^{2}$ Microwave \& Wireless Research Laboratory, Dept. of Electrical \& Computer Engineering, Dalhousie University, Halifax, Nova Scotia, Canada B3J 2X4 (email: farid.jolani@dal.ca, zdchen@dal.ca)

${ }^{3}$ Department of Communication Engineering, East China Jiaotong University, Nanchang 330013, China

${ }^{4}$ Center for Communications Technology, Faculty of Life Sciences and Computing, London Metropolitan University, London N7 $8 \mathrm{DB}, \mathrm{UK}$
\end{abstract}

Abstract- A balanced antipodal bow-tie antenna for Ultra-wideband (UWB) applications is presented. It is printed on a single layered FR4 substrate of a small volume of $26 \times 31 \times 1.6 \mathrm{~mm}^{3}$. It is featured a staircase bow-tie radiator for bandwidth enhancement and size reduction, a tapered microstrip feeding balun for balance to unbalance transfer, two dumb-bell shaped slots and an L-shaped meander stub for bandnotching. Simulated and measured results show a good agreement with each other: the proposed antenna operates at 2.8-11 GHz, fully satisfy the UWB requirements, and provides two notch-bands at 3.3-4 GHz and 5-6 GHz, respectively. Such notch bands minimize interference to/from the existing WiMAX and WLAN networks.

Index Terms - Ultra-wideband, double notch-bands, balun, balanced antipodal antenna.

\section{INTRODUCTION}

As a leading technology for future short-distance wireless applications, the ultra-wideband (UWB) wireless communication presents technical challenges on antenna design. This type of antennas should fully comply with the UWB emission mask requirements in the wide frequency band of 3-11 GHz while retain compactness for uses in the applications, such as high-speed wireless communication links and radar imaging. [1]. A good UWB antenna should also possess features such as easy fabrication, good impedance-matching characteristics, gain flatness, and a relatively low group delay across the whole operating band.

Various types of antipodal and tapered slot antennas have been shown to be promising candidates for ultra -wideband technology and applications, such as Vivaldi, bow-tie and tapered slot antennas (TSA) [2-5]. In [6], a miniaturized antipodal antenna is proposed to cover the UWB operational band; it utilizes a microstrip feeder that is directly connected to the radiator as well as ground plane to reduce the antenna dimensions. In [7], a balanced antipodal with dimension of $56 \times 76 \mathrm{~mm}^{2}$ is proposed for gain enhancement of the antenna based on substrate shaping. However, it requires two substrates in order to obtain a balanced current flows and radiation characteristics.

In [8], a new miniaturized notch-band elliptically tapered slot antenna is presented and it has a size of $0.63 \lambda_{g} \times 0.64 \lambda_{g}$ where $\lambda_{g}$ is effective wavelength at $3.1 \mathrm{GHz}$ with an effective dielectric constant of 2.65 and the substrate thickness of $0.8 \mathrm{~mm}$. The structure exhibits a signal rejection at $5 \mathrm{GHz}-6 \mathrm{GHz}$ with the gain suppression of up to $15 \mathrm{~dB}$. However, this design has an undesired radiation pattern in the H-plane and only provides notch rejection to the WLAN band of IEEE 802.11a standard (not WiMAX). [9] Proposes a novel tapered slot antenna operating from 2.4 to $11.2 \mathrm{GHz}$ with Archimedean spiral-shaped slot as the open-circuit circular stub to obtain a notch-frequency band from 4.6 to $6.2 \mathrm{GHz}$. The antenna has a size of $0.91 \lambda_{g} \times 0.91 \lambda_{g}$ with effective dielectric constant of 3.3 and a substrate thickness of $0.8 \mathrm{~mm}$. In this letter, a new antenna is proposed for the design of a compact balanced antipodal antenna that fully covers the UWB frequency range from $3.1-10.6 \mathrm{GHz}$ and provides double notch-bands at $3.3-4 \mathrm{GHz}$ 
(WiMAX) and 5-6 GHz (WLAN). In comparison with the previous antenna designs reported in [8, 9], the proposed antenna is more compact, and has a smaller cross-sectional dimension of $0.49 \lambda_{g} \times 0.58 \lambda_{g}$, where $\lambda_{g}$ is effective wavelength at $3.1 \mathrm{GHz}$ with an effective dielectric constant of 3.3 and a substrate thickness of $1.6 \mathrm{~mm}$. The notch band of 3.3-4 GHz mitigates interference to/from the existing WiMAX networks. Moreover, it possesses an omni-directional pattern along the H-plane and dipole-like radiation pattern in the E-plane over the whole frequency band.

\section{ANTENNA STRUCTURE}

The geometric design of the proposed antenna is shown in Fig. 1. The antenna consists of two staircase rounded bow-tie radiators that are symmetrically connected to a tapered microstrip feeder. At the bottom of the substrate, a tapered ground of the microstrip is designed to realize a balanced tapered transition of the surface currents that will in turn yield balanced radiation patterns. The design was evolved from a bow-tie antenna with rectangular patches of a length of $12.23 \mathrm{~mm}$ (L1) and a width of $12.25 \mathrm{~mm}$ $(\mathrm{W} 1+\mathrm{W} 2+\mathrm{W} 3+\mathrm{W} 4+\mathrm{W} 5)$ which is a quarter of guided wavelength at $3.1 \mathrm{GHz}$. The fed sides of the patches were then reshaped in a staircase manner as shown in Fig. 1 with step increment of the staircase being chosen to be the quarter wavelengths at different frequencies, which different notches were createc at the bottom of the rounded bow-tie antenna [10]. More specifically, the length of L2 $=10.59 \mathrm{~mm}$ is a quarter of the guided wavelength at $4 \mathrm{GHz}$, whereas the length of $\mathrm{L} 3$ is a quarter of guided wavelength at $6.5 \mathrm{GHz}$.

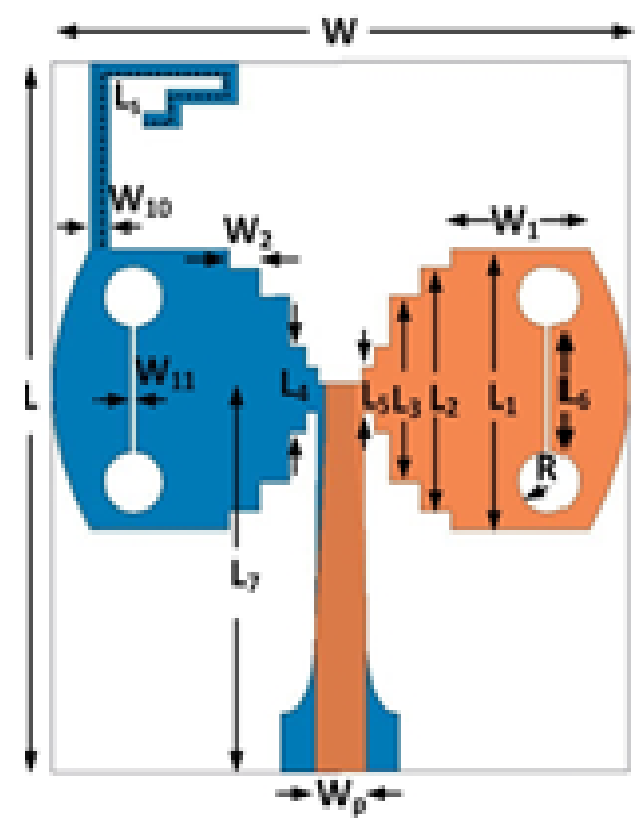

(a)

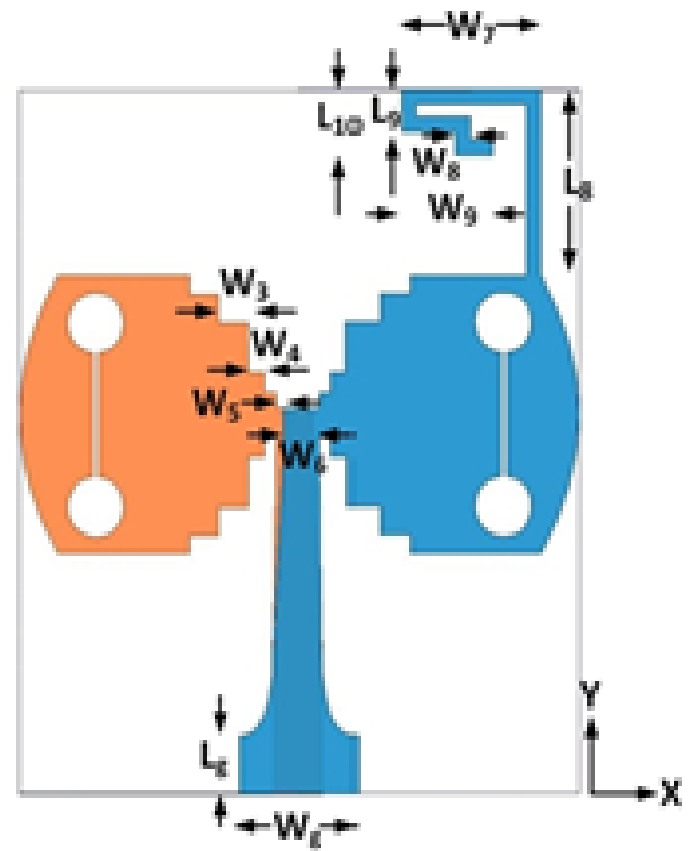

(b)

Figure 1 Configuration of the proposed antenna (a) top view, (b) bottom view.

To achieve a notch-band at WLAN band of 5-6 GHz, two dumb-bell shaped slots are etched symmetrically on the two sides of the bowtie; whereas to provide a rejection band at WiMAX band (3.3-4 $\mathrm{GHz}$ ), a meander open-circuit stub is added to one arm of staircase bowtie. The overall dimension of the antenna is $26 \times 31 \mathrm{~mm}^{2}$. Table I. shows the design parameters of the proposed antenna. 
TABLE I PARAMETERS OF THE PROPOSED ANTIPODAL BOW-TIE ANTENNA (IN MM)

\begin{tabular}{|c|c|c|c|}
\hline $\mathbf{W}$ & 26 & $\mathbf{L}$ & 31 \\
\hline$W_{1}$ & 6.14 & $\mathbf{L}_{1}$ & 12.23 \\
\hline $\mathrm{W}_{2}$ & 1.37 & $\mathbf{L}_{2}$ & 10.59 \\
\hline $\mathbf{W}_{3}$ & 1.4 & $\mathbf{L}_{3}$ & 8.12 \\
\hline $\mathbf{W}_{4}$ & 0.71 & $\mathbf{L}_{4}$ & 3.73 \\
\hline$W_{5}$ & 0.54 & $\mathbf{L}_{5}$ & 1.94 \\
\hline $\mathrm{W}_{6}$ & 1.7 & $\mathrm{~L}_{6}$ & 5.44 \\
\hline $\mathbf{W}_{7}$ & 6.52 & $\mathbf{L}_{7}$ & 16.97 \\
\hline $\mathrm{W}_{8}$ & 0.67 & $\mathbf{L}_{8}$ & 8.19 \\
\hline$W_{9}$ & 4.27 & $\mathbf{L}_{9}$ & 1.85 \\
\hline$W_{10}$ & 0.67 & $\mathrm{~L}_{10}$ & 2.88 \\
\hline $\mathbf{W}_{11}$ & 0.25 & $\mathbf{L}_{\mathrm{s}}$ & 21.85 \\
\hline $\mathbf{W}_{\mathrm{g}}$ & 5.4 & $\overline{\mathbf{R}}$ & 1.33 \\
\hline$W_{p}$ & 2.3 & & \\
\hline
\end{tabular}

Various lengths of the open-circuit stub $L_{s}$ were simulated using the CST Microwave Studio Simulator to determine the rejection performance for the WiMAX band. Simulation results are shown in Fig. 2. It is clearly seen that by increasing the length of the open-circuit from $14.85 \mathrm{~mm}$ to $21.85 \mathrm{~mm}$, the notch resonant frequency changes from 4.2 to $3.5 \mathrm{GHz}$. In the final design, the length of the open circuit stub was set to be $21.85 \mathrm{~mm}$, which is the half of the guided wavelength at the center frequency of WIMAX band.

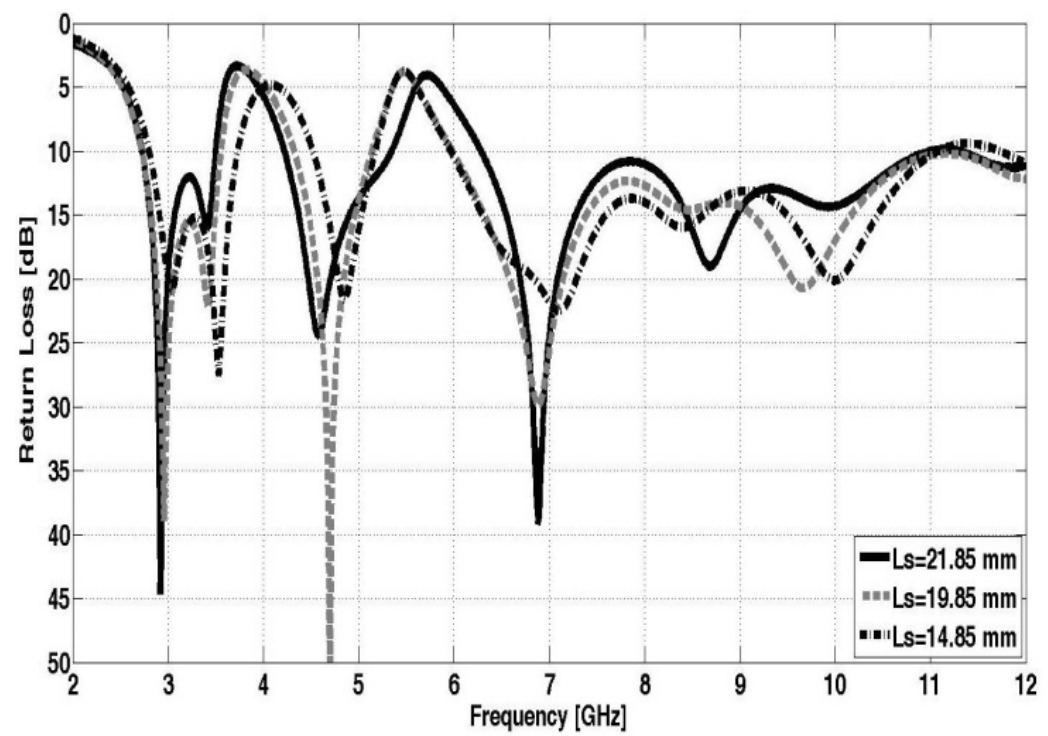

Figure 2 Simulated reflection coefficients of the proposed antenna with different lengths of an open-circuit stub.

The dumb-bell slots on the both sides of the bow-tie radiators, as depicted in Fig. 1, were simulated for assessment of the rejection performance at 5-6 GHz. The results are shown in Fig. 3. In the initial design, the radius of the circular slots and the length of the thin connecting slot were chosen to give a total current path of a quarter of the guided wave length at the center frequency of the WLAN band. As shown, with 
the decrease in the radius of the dumb-bell slots, the center frequency of the second notch-band shifts from $5.5 \mathrm{GHz}$ upward to $8 \mathrm{GHz}$, whereas the magnitude of the return-loss reduces.

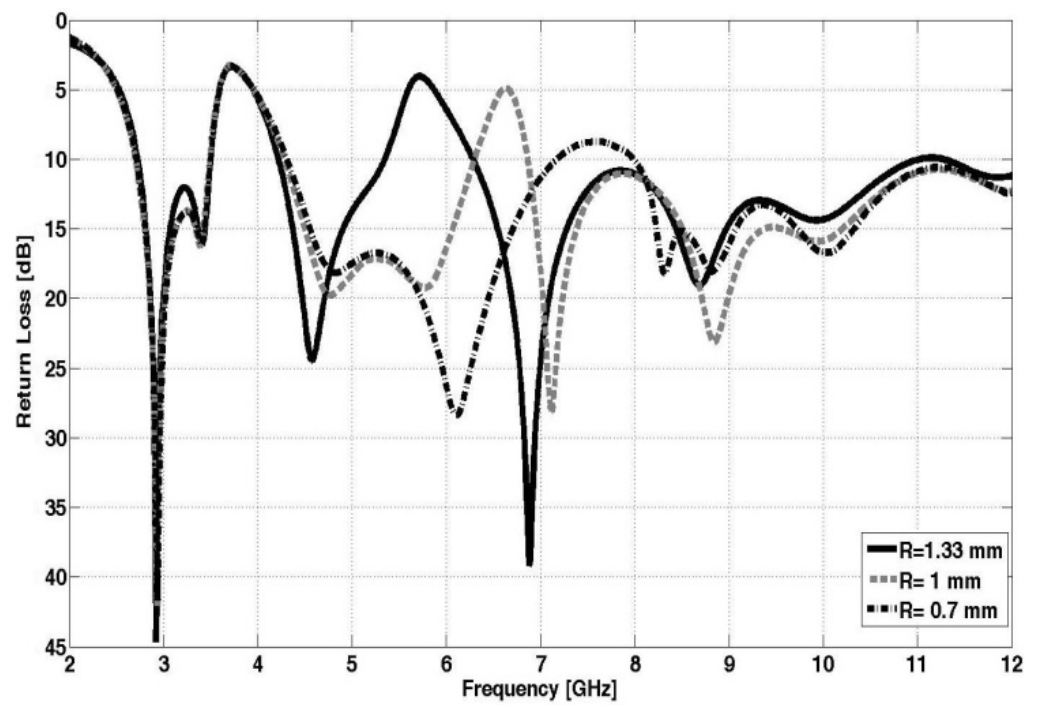

Figure 3 Simulated reflection coefficients of the proposed antenna with different radius of the dumb-bell

As shown in Fig.4, by changing the length of feedline $\left(\mathrm{L}_{7}\right)$ from $16.97 \mathrm{~mm}$ to $20.97 \mathrm{~mm}$, the impedance matching, in particular at high frequencies, would deteriorate. Moreover, lower frequency would shift slightly downward. By optimization, the best value of L7 was found at $16.97 \mathrm{~mm}$ that is used in this design.

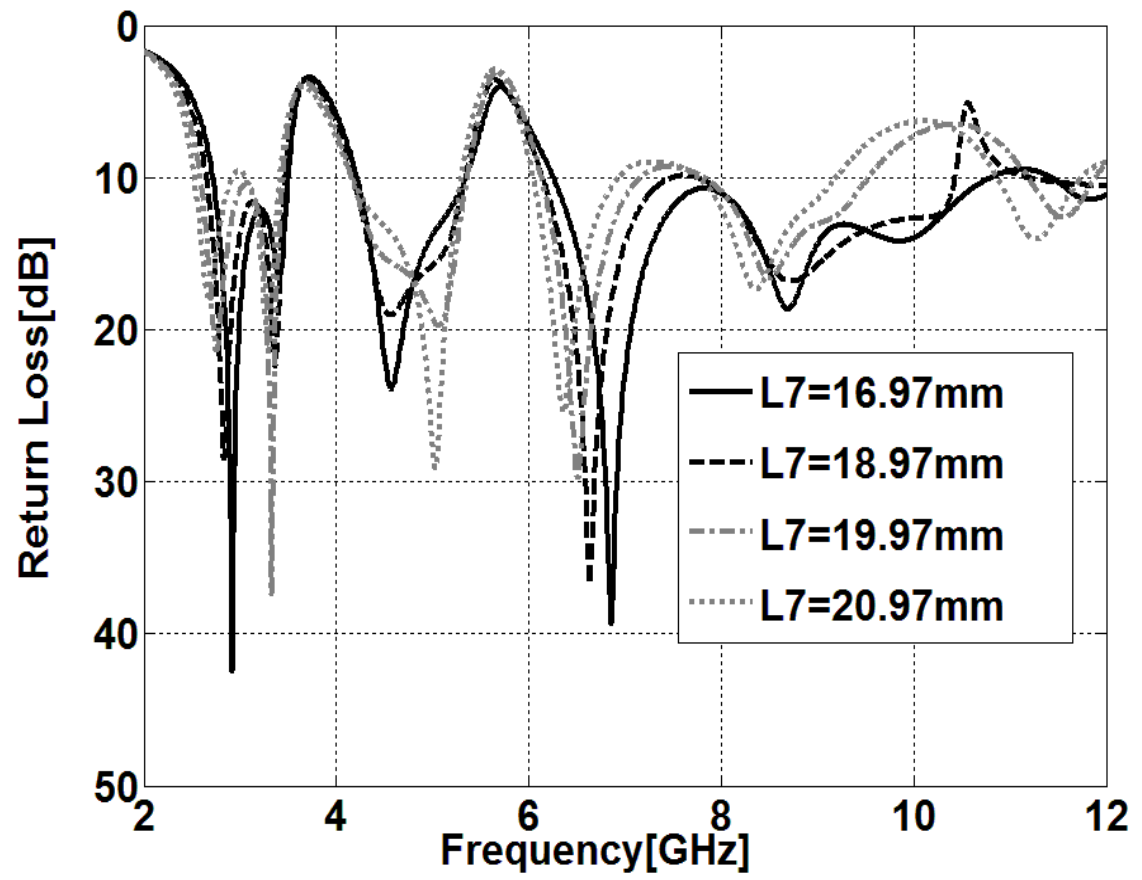

Fig. 4. Simulated reflection coefficients of the proposed antenna with different feedline (L7)

The surface current distributions of the antenna are depicted in Fig. 5 and Fig. 6. At $5.5 \mathrm{GHz}$, the center frequency of the second notch- band for WLAN, strong surface currents flow around the dumb-bell slots. 
In other words, the dumb-bell slots act effectively as short-circuit stubs of a quarter wavelengths. At 3.5 $\mathrm{GHz}$ of the WiMAX band, asymmetric surface current distribution is observed on the two sides of the substrate, andthe surface current concentrates on the L-shaped stub, and flow to the open-end and returning back with little radiation. This results in the band-notched behavior of the antenna at $3.5 \mathrm{GHz}$.

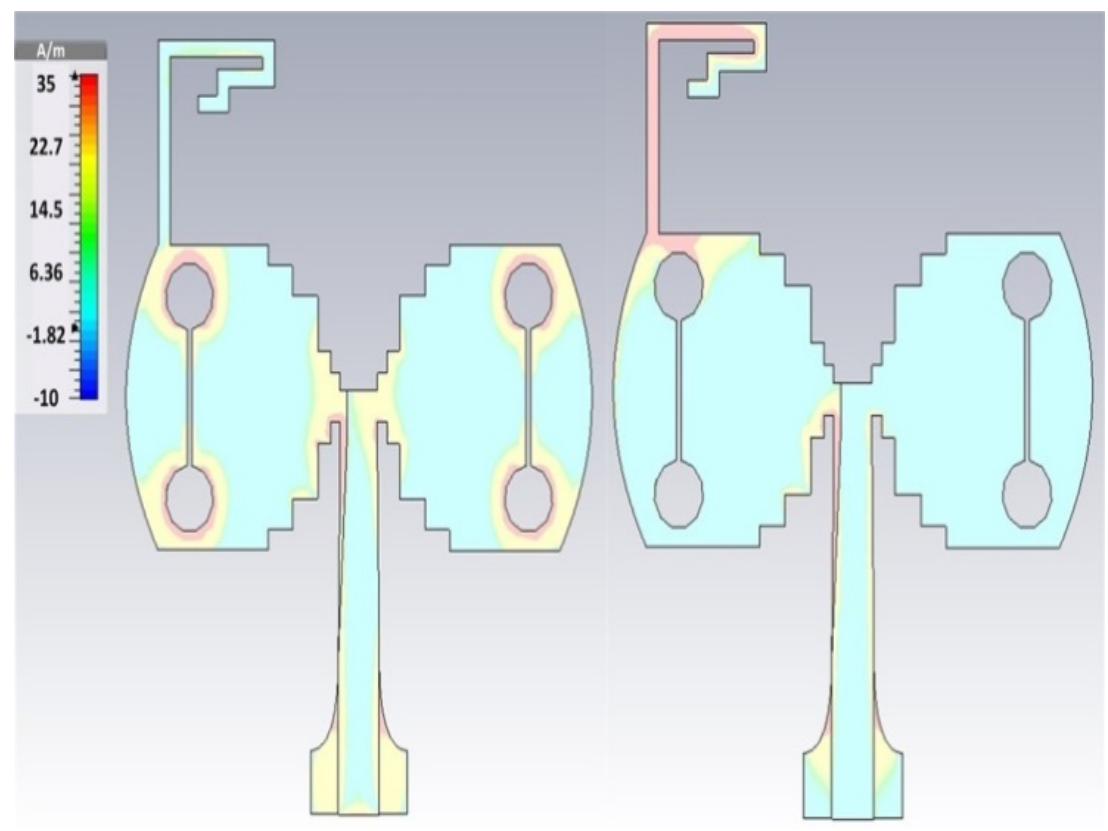

(a)

(b)

Figure 5 Simulated surface current density of the proposed antenna at (a) $5.5 \mathrm{GHz}$ (b) $3.5 \mathrm{GHz}$.

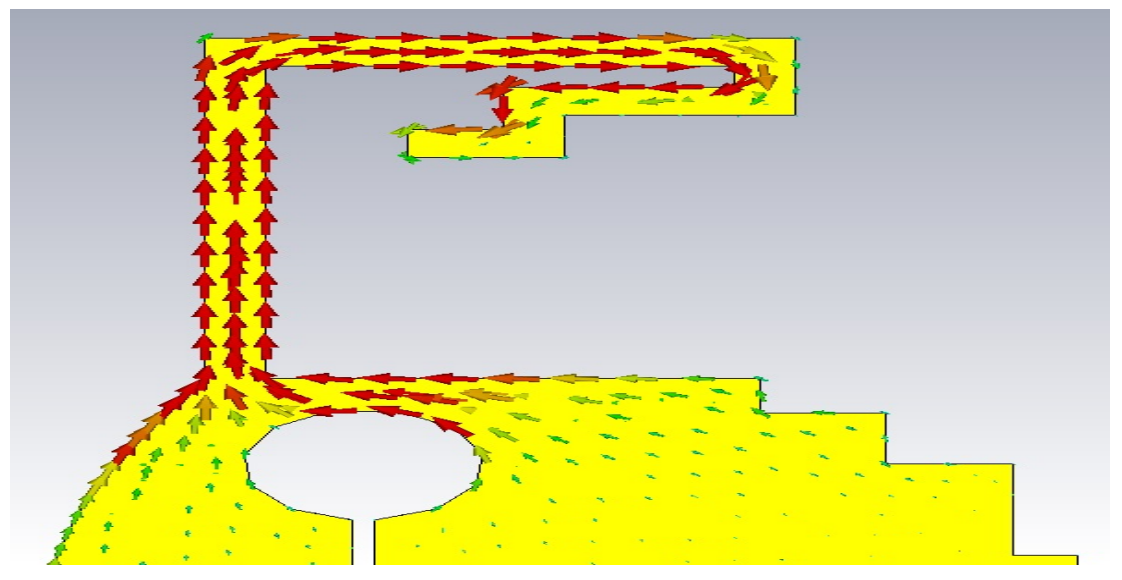

Figure 6 The simulated magnitude of current density of the proposed antenna at $3.5 \mathrm{GHz}$.

\section{TEST RESUlts AND Discussions}

The proposed antenna was fabricated on FR4 substrate with an overall size of $26 \mathrm{~mm} \times 31 \mathrm{~mm}$, the dielectric constant of 4.4, and a thickness of $1.6 \mathrm{~mm}$. A snapshot of the fabricated antenna is shown in Fig. 7. The return loss of the antenna was measured and compared to the simulation results. As shown in Fig. 8, a good agreement is observed; the results show that the proposed antenna exhibits an ultra-wide 
impedance bandwidth, covering from 2.8 to $11 \mathrm{GHz}$ with $10 \mathrm{~dB}$ return loss reference. It also provides two notch-bands at 3.3-4 GHz and 5-6 GHz.

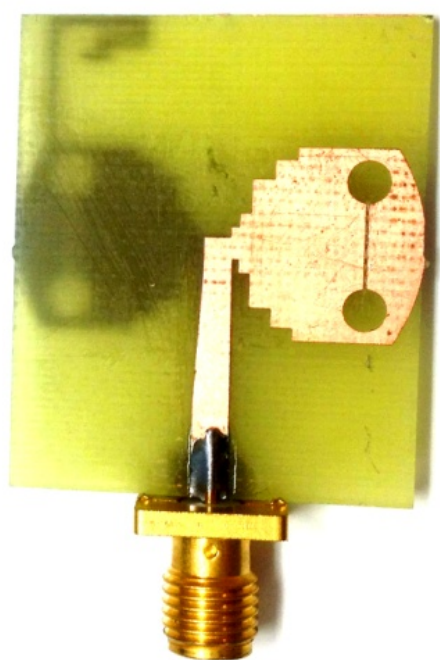

(a)

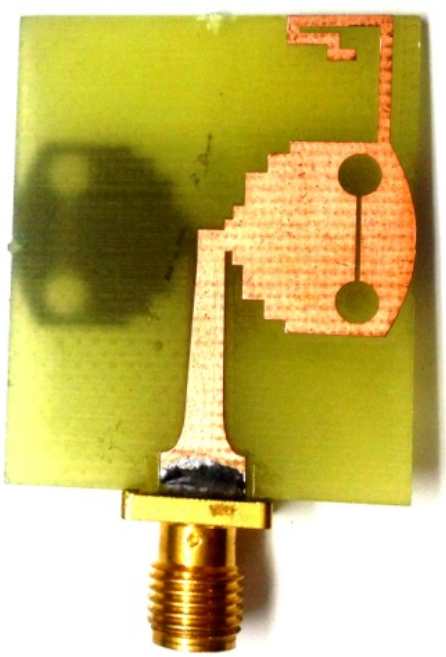

(b)

Figure 7 Photos of the (a) top and (b) bottom layers of the fabricated antenna.

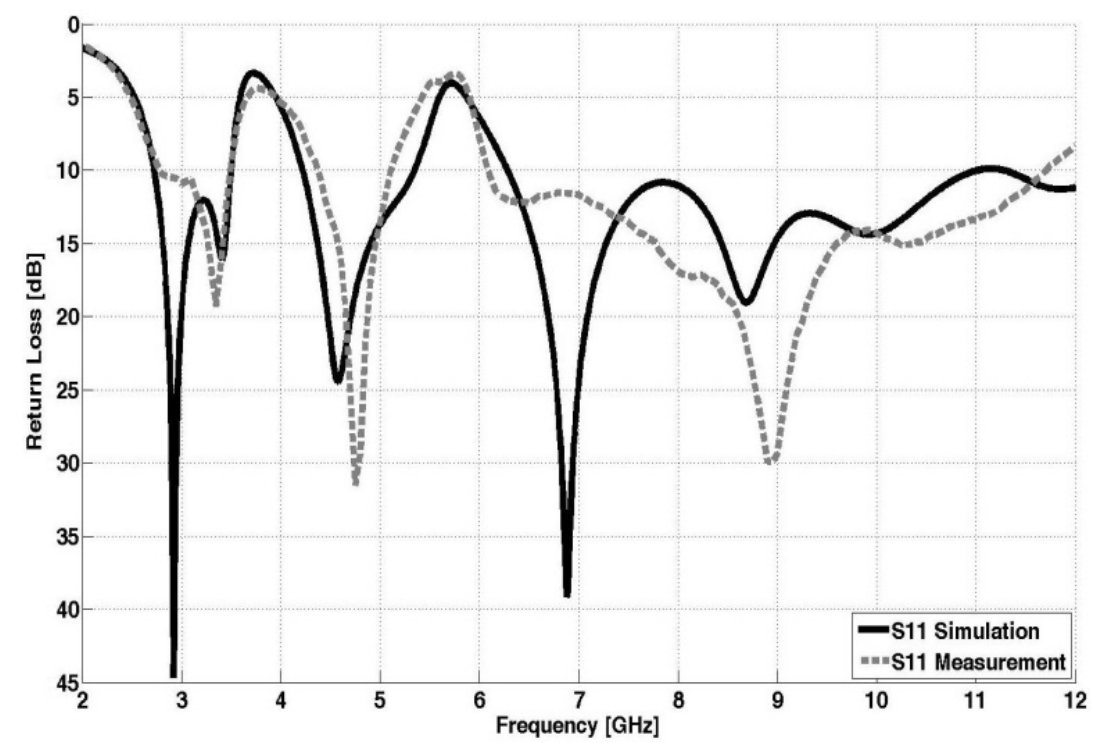

Figure 8 The simulated and measured reflection coefficients of the proposed antenna.

The measured and simulated gain of the proposed antenna at different frequencies is depicted in Fig. 9. It shows that the proposed antenna exhibits a significantly lower gain at the notch bands than at other frequencies. The measured gain is reduced from $2 \mathrm{~dB}$ to $-5 \mathrm{~dB}$, when operating frequency increases from $3 \mathrm{GHz}$ to a $3.6 \mathrm{GHz}$, whereas there is a $13 \mathrm{~dB}$ drop in the measured gain at the center frequency of the second notch band. An overall gain of $3.5 \mathrm{~dB}$ across the frequency range of $6.1-11 \mathrm{GHz}$ is observed. 


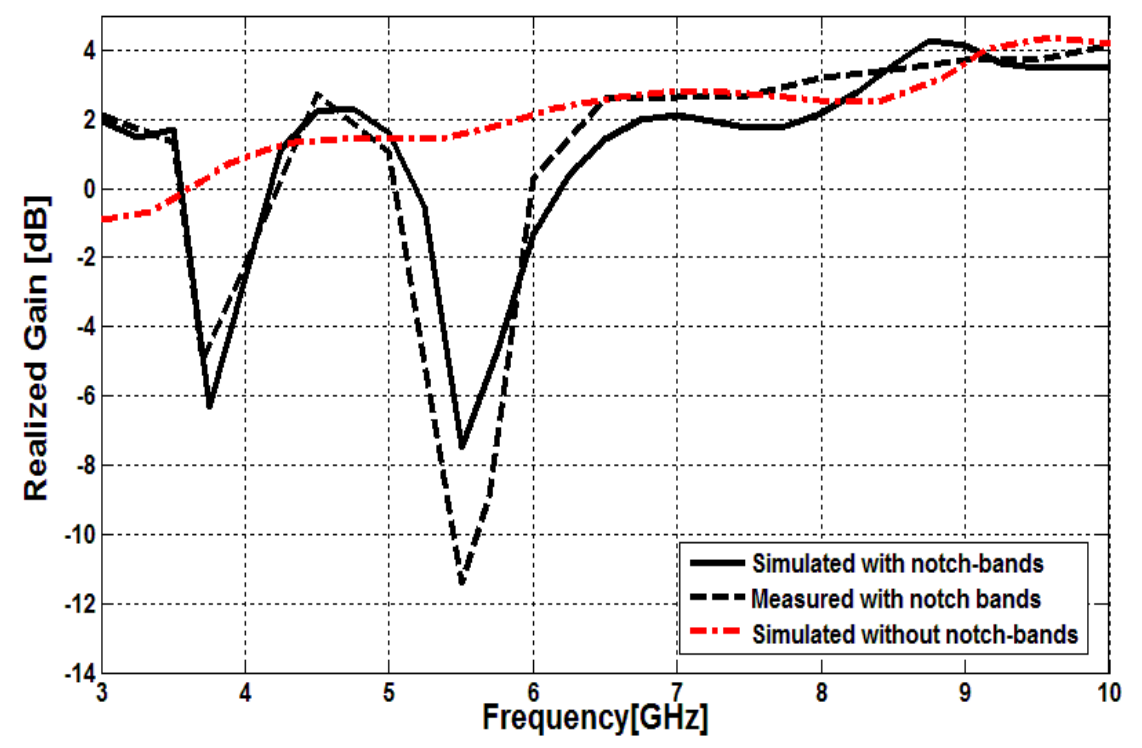

Figure 9 The measured and simulated realized gain of the proposed antenna.

The radiation patterns of the proposed antenna in the two principal planes at $4.5 \mathrm{GHz}, 6.5 \mathrm{GHz}$ and 10 $\mathrm{GHz}$ are plotted in Fig. 10. It is observed that there is a good agreement between simulated and measured patterns and the measured cross-polarization is less than the co-polarization by more than $15 \mathrm{~dB}$ in both planes. In addition, the antenna exhibits an omni-directional pattern along the H-plane and dipole-like pattern in the E-plane.

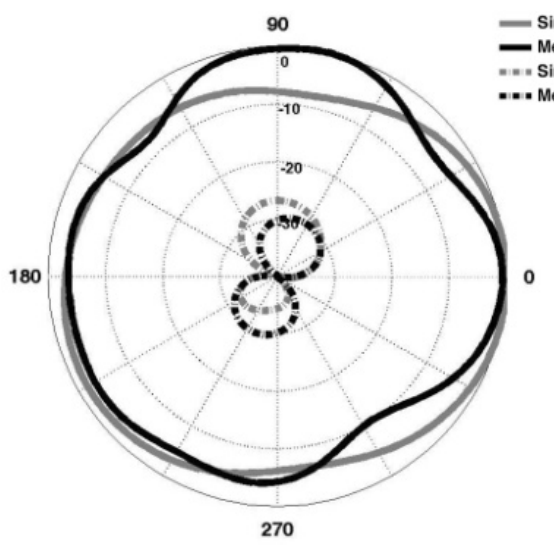

(a)

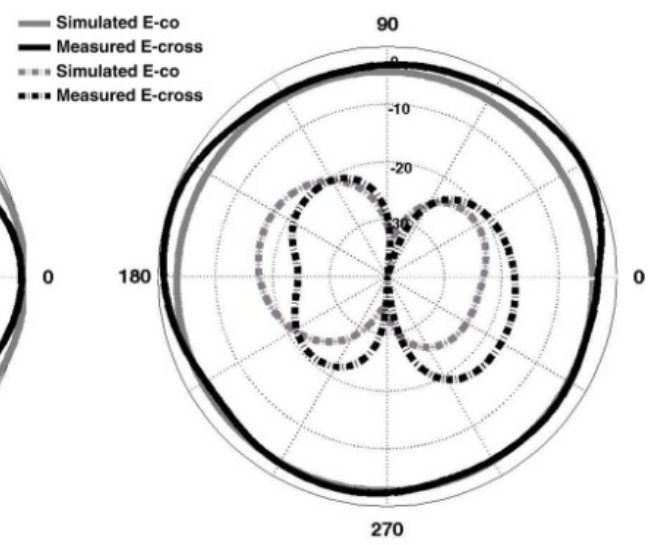

(b) 


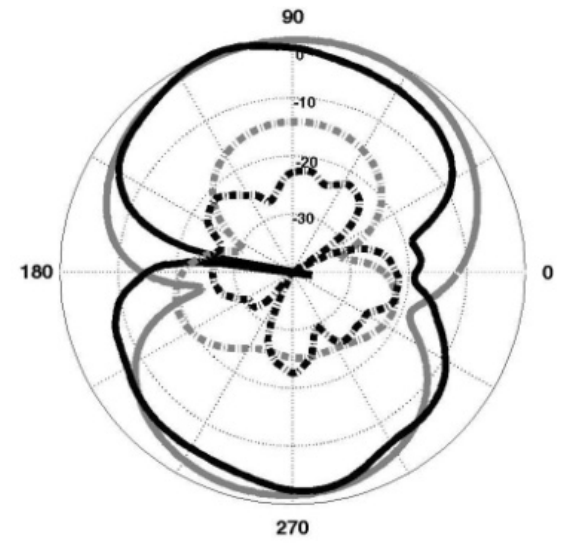

(c)

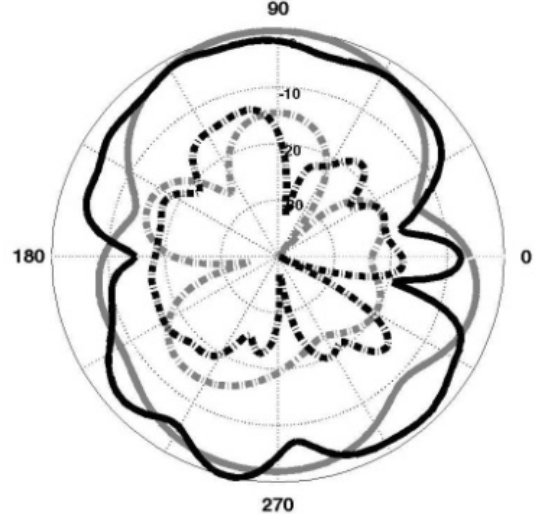

(e)

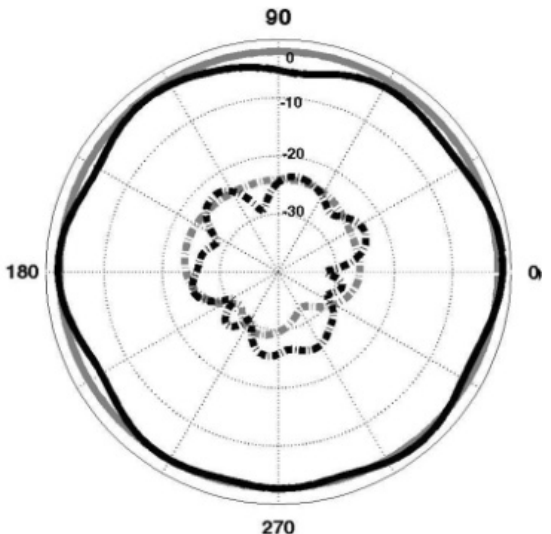

(d)

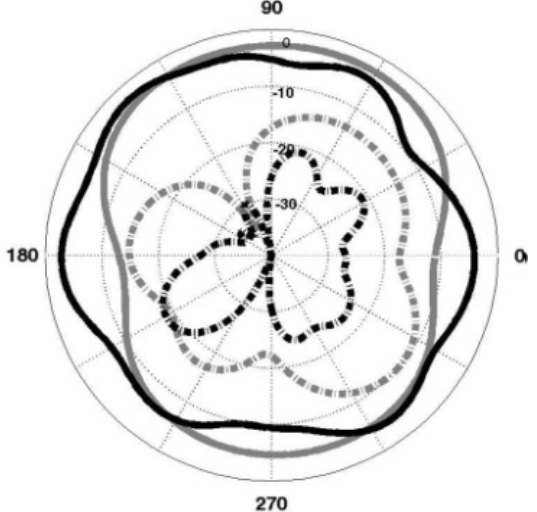

(f)

Figure 10 Simulated and measured radiation patterns of the proposed antenna, on (a) E-plane at $4.5 \mathrm{GHz}$, (b) $\mathrm{H}$ plane at $4.5 \mathrm{GHz}$, (c) E-plane at $6.5 \mathrm{GHz}$, (d) H-plane at $6.5 \mathrm{GHz}$, (e) E-plane at $10 \mathrm{GHz}$, (f) H-plane at $10 \mathrm{GHz}$.

\section{CONCLUSION}

A balanced antipodal antenna for UWB applications has been presented. It is a microstrip-fed antenna that comprises of a staircase rounded bow-tie radiatorand a tapered microstrip feeding balun. In addition, an L-shaped open circuit meander stub and two dumb-bell slots have been applied to the radiating element at the bottom and top plane of the antenna; they create two notch bands centre at $3.5 \mathrm{GHz}$ and $5.5 \mathrm{GHz}$, respectively, for the WiMAX and WLAN bands. The compactness and simplicity of the design with, omnidirectional radiation pattern, ultra-wideband performance, and dual-band notch function make the proposed antenna suitable for uses in the UWB wireless communication applications.

\section{REFERENCES}

[1] H. Schantz, The art and science of ultra-wideband antennas, Norwood, MA: Artech House, 2005.

[2] P.J. Gibson, "The vivaldi aerial," in Proc. 9th Eur. Microw. Conf., 1979, pp.101-105.

[3] G. Zheng, A.A. Kishk, A.W. Glisson, and A.B. Yakovlev, "A broadband printed bow-tie antenna with a simplified balanced feed," Microw. Opt. Technol. Lett., vol. 47, no. 6, pp. 534-536, Dec. 2005.

[4] K. Kiminami, A. Hirata, and T. Shiozawa, "Double-sided printed bow-tie antenna for UWB communication," IEEE Antennas Wireless Propag. Lett., vol. 3, pp. 152-153, 2004.

[5] A. Abbosh, M. Bialkowski, and H. Kan, "Planar tapered slot antennas," in Printed Antennas for Wireless Communications Handbook, R. Waterhouse, Ed. Hoboken, NJ: Wiley, 2007, ch. 6. 
[6] A.M. Abbosh, "Miniaturized microstrip-fed tapered-slot antenna with ultrawideband performance," IEEE Antennas Wireless Propag. Lett., vol. 8, pp. 690-692, 2009.

[7] Kota, K. and L. Shafai, "Gain and radiation pattern enhancement of balanced antipodal Vivaldi antenna," Electron. Lett., vol. 47, no. 5, pp. 303-304, 2011.

[8] F. Zhu, S. Gao, A.T.S. Ho, R.A. Abd-Alhameed, C.H. See, J. Li, X. Jiadong, "Miniaturized tapered slot antenna with signal rejection in $5-6-\mathrm{GHz}$ band using a balun," IEEE Antennas Wireless Propag. Lett., vol. 11, pp. 507-510, 2012.

[9] D.H. Lee, H.Y. Yang, and Y.K. Chao, "Tapered slot antenna with band-notched function for ultrawideband radios," IEEE Antennas Wireless Propag. Lett., vol. 11, pp. 682-685, 2012.

[10] S.W. Su, K.L. Wong, and C.L. Tang, "Ultra-wideband square planar monopole antenna for IEEE 802.16a operation in. the 2-11 GHz band," Microwave and Optical Tech. Lett., vol. 42, no.6 pp. 463-466, 2004. 